\title{
Management of patients with hormone receptor- positive breast cancer with visceral disease: challenges and treatment options
}

This article was published in the following Dove Press journal:

Cancer Management and Research

21 January 2015

Number of times this article has been viewed

\section{Wael A Harb}

Horizon Oncology Center, Lafayette, IN, USA

Video abstract

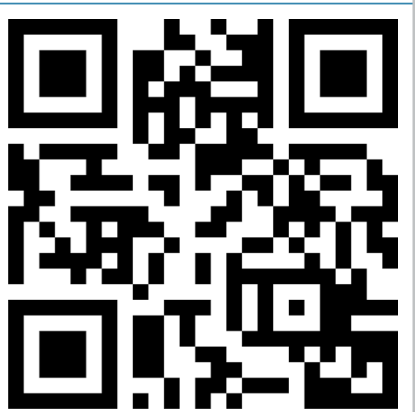

Point your SmartPhone at the code above. If you have a QR code reader the video abstract will appear. Or use: http://dvpr.es/lulgyil
Correspondence: Wael A Harb Horizon Oncology Center, 1345 Unity Place, Suite 365, Lafayette, IN 47905, USA

Tel + I 7654465 I II

Fax +I 7658380972

Email wharb@horizonbioadvance.com
Abstract: Endocrine therapy is an important treatment option for women with hormone receptor-positive $(\mathrm{HR}+)$ advanced breast cancer $(\mathrm{ABC})$, yet many tumors are either intrinsically resistant or develop resistance to these therapies. Treatment of patients with $\mathrm{ABC}$ presenting with visceral metastases, which is associated with a poor prognosis, is also problematic. There is an unmet need for effective treatments for this patient population. Although chemotherapy is commonly perceived to be more effective than endocrine therapy in managing visceral metastases, patients who are not in visceral crisis might benefit from endocrine therapy, avoiding chemotherapy-associated toxicities that might affect quality of life. To improve outcomes, several targeted therapies are being investigated in combination with endocrine therapy for patients with endocrine-resistant, $\mathrm{HR}+\mathrm{ABC}$. Although available data have considered patients with HR+ $\mathrm{ABC}$ as a whole, there are promising data from a prespecified analysis of a Phase III study of everolimus (Afinitor ${ }^{\circledR}$ ), a mammalian target of rapamycin (mTOR) inhibitor, in combination with exemestane $\left(\right.$ Aromasin $\left.^{\circledR}\right)$ in patients with visceral disease progressing after nonsteroidal aromatase inhibitor therapy. In this review, challenges and treatment options for management of $\mathrm{HR}+\mathrm{ABC}$ with visceral disease, including consideration of therapeutic approaches undergoing clinical investigation, will be assessed.

Keywords: endocrine resistance, endocrine therapy, targeted therapy

\section{Introduction}

Breast cancer (BC) is the most common cancer and leading cause of cancer death in women worldwide; in 2008 there were 1.38 million new cases and 458,400 BC deaths. ${ }^{1}$ In the United States, BC is the second leading cause of cancer-related death among women, with an estimated 40,000 BC deaths expected in $2014 .^{2}$

Up to $80 \%$ of $\mathrm{BCs}$ are hormone receptor-positive (HR+) (either estrogen receptor [ER]-positive or progesterone receptor-positive), ${ }^{3}$ and a strong correlation between hormone status and menopausal status is suggested: approximately $75 \%$ of BCs in postmenopausal women are HR+ compared with only $50 \%$ in premenopausal women. ${ }^{4}$

The ER was the first cancer target used in the management of BC; at least two forms of ER are now recognized (ER $\alpha$ and $E R \beta) .{ }^{5}$ Current endocrine therapies for BC include selective ER modulators that inhibit estrogen binding to the ER, and nonsteroidal and steroidal aromatase inhibitors (AIs) that suppress estrogen synthesis through the aromatase pathway. Other available endocrine therapies include pure ER antagonists, progestins, and luteinizing hormone-releasing hormone (LHRH) agonists. ${ }^{6,7}$

Endocrine therapy is an important systemic treatment option for pre- and postmenopausal women with advanced $\mathrm{BC}(\mathrm{ABC}) \cdot{ }^{8-10}$ For most premenopausal patients 
with $\mathrm{HR}+\mathrm{ABC}$ after tamoxifen therapy, ovarian suppression or ablation in combination with endocrine therapy is recommended. For recurrence within 1 year of antiestrogen exposure, surgical or radiotherapeutic oophorectomy or LHRH agonists with endocrine therapy should be considered, while initial treatment with an antiestrogen alone, or ovarian suppression or ablation plus endocrine therapy is advised for those without previous exposure. ${ }^{7}$ Treatment with third-generation AIs, including letrozole (Femara $^{\circledR}$; Novartis Pharmaceuticals Corporation, East Hanover, NJ, USA), anastrozole (Arimidex ${ }^{\circledR}$; AstraZeneca Pharmaceuticals LP, Wilmington, DE, USA), and exemestane (Aromasin ${ }^{\circledR}$; Pfizer Inc., New York, NY, USA), has become the standard first-line treatment (ie, the first treatment given) for postmenopausal women with ABC. Use of these agents has improved progression-free survival (PFS) and overall survival (OS) compared with other endocrine therapies, including tamoxifen. ${ }^{11,12}$ However, the long-term effectiveness of endocrine therapies is limited because of disease relapse and resistance. ${ }^{13}$

The 5 -year survival rate for BC is only $24 \%$ in patients with distant metastases, ${ }^{14}$ with a higher overall incidence of metastatic disease at diagnosis in older over younger women. ${ }^{15}$ Many postmenopausal women with $\mathrm{HR}+\mathrm{ABC}$ present with visceral metastases, ${ }^{16}$ with a general pattern of metastatic spread involving either soft tissues or bone metastases or involving visceral organs, such as the liver, peritoneum, lung, and pleura. ${ }^{8}$ First metastasis is reported to occur in the skeletal system in $46 \%$, in the visceral organs in $41 \%$, and in both systems in $13 \%$ of patients, with the disease remaining confined to the skeleton or visceral system in nearly $60 \%$ of patients and developing into bone and visceral metastases in more than $40 \%$ of patients. ${ }^{17}$

The prognosis for postmenopausal women with HR+ $\mathrm{ABC}$ is correlated with the size and stage of the primary tumor at diagnosis, the disease-free interval from diagnosis, the type of adjuvant therapy received, and the extent and pattern of metastasis of the disease. ${ }^{8,18}$ Prognosis is worse in patients with metastases involving visceral organs than in those without visceral organ involvement. ${ }^{10,17-20}$ In early clinical trials of first-line nonsteroidal AIs, OS was 18-24 months for patients with visceral metastases and approximately 40 months for patients without visceral disease. ${ }^{21}$

Although endocrine therapy benefits patients with $\mathrm{ABC}$, the clinical benefit and time to disease progression are comparatively less in patients with visceral metastases than in patients with no visceral metastases. ${ }^{21}$ As a result, there is an unmet need for effective treatments for postmenopausal women with $\mathrm{HR}+\mathrm{ABC}$ with visceral disease, a patient population with a particularly poor prognosis.

\section{Current recommendations for patients with visceral disease}

Chemotherapy is commonly perceived to be more effective than endocrine therapy in patients with visceral metastases, and it is generally believed that endocrine therapy should be avoided in such cases. ${ }^{22-24}$ However, current guidelines recommend endocrine therapy for postmenopausal women with $\mathrm{HR}+\mathrm{ABC}$, with the exception of patients with visceral crisis, defined as the presence of lymphangitic lung metastases, bone marrow replacement, carcinomatous meningitis, or significant liver metastases. ${ }^{25}$ In visceral crisis, current guidelines recommend chemotherapy to achieve rapid symptom control. ${ }^{7,25-27}$

The National Comprehensive Cancer Network ${ }^{\circledR}$ $\left(\mathrm{NCCN}^{\circledR}\right)$ Clinical Practice Guidelines in Oncology (NCCN Guidelines $^{\circledR}$ ) note that because systemic treatment of BC recurrence or metastatic disease prolongs survival and enhances quality of life (QoL) but is not curative, use of minimally toxic endocrine therapies is preferable to cytotoxic therapy whenever reasonable. It is recommended that patients with symptomatic visceral metastases receive chemotherapy, whereas patients with asymptomatic visceral disease receive endocrine therapy. ${ }^{7}$ Contrary to current treatment guidelines, a substantial proportion of patients with visceral disease who are not in visceral crisis and, therefore, not in need of immediate symptom control, may also benefit from treatment with endocrine therapy. ${ }^{8}$ In such cases, the need for chemotherapy could be delayed (and its associated toxicity avoided) with use of endocrine therapy. ${ }^{8,22,24}$

\section{Resistance to endocrine therapy}

Clinical studies have shown the comparative efficacy of endocrine therapies as first- and second-line treatment (ie, the treatment given after failure of first-line therapy) in patients with $\mathrm{ABC}$ with visceral metastases. For example, second-line treatment with anastrozole vs megestrol acetate (Megace $^{\circledR}$; Bristol-Myers Squibb Company, Princeton, NJ, USA) in two Phase III trials for ABC showed a clinical benefit rate (CBR) of $31 \%$ and $32 \%$, respectively, in patients with visceral metastases compared with $52 \%$ and $47 \%$, respectively, in patients without visceral metastases. ${ }^{21}$ Firstline treatment with anastrozole vs tamoxifen in two Phase III trials showed a CBR of $50 \%$ and $47 \%$, respectively, in patients with visceral metastases compared with $62 \%$ and $56 \%$, respectively, in patients without visceral disease. ${ }^{21}$ 
Similarly, a comparative study of exemestane vs anastrozole for patients with visceral disease reported a CBR of $32 \%$ in patients treated with anastrozole vs $38 \%$ in patients treated with exemestane. ${ }^{28}$ However, despite the continued presence of the ER, many breast tumors show either primary resistance to endocrine therapies or develop secondary resistance after initial responsiveness, thereby limiting the success of this therapeutic strategy. ${ }^{5,29-33}$

Responses with tamoxifen are not durable, with mean response durations of only 9 to 12 months in metastatic BC. ${ }^{34}$ Similarly, resistance has been observed with AIs within 1-2 years. ${ }^{34}$ Treatment options are notably limited in patients with visceral metastases, particularly in those whose disease has progressed during or after nonsteroidal AI treatment. ${ }^{8}$ As a result, there is an unmet need for new strategies to enhance the effectiveness of endocrine therapies in patients with visceral disease. ${ }^{35}$

Mechanisms involved in acquired and intrinsic resistance to endocrine therapy are being elucidated. ${ }^{23,29,34,36-41}$ Endocrine resistance might be the result of complex adaptive changes in BC cells that are, in part, attributable to long-term endocrine treatment, with resultant prolonged estrogen deprivation with long-term endocrine therapy playing a role in the development of resistance. ${ }^{42}$ Another resistance mechanism involves the interaction of the ER signaling pathway with the phosphoinositide 3 kinase/protein kinase $\mathrm{B} /$ mammalian target of rapamycin (PI3K/Akt/mTOR) pathway. ${ }^{34} \mathrm{mTOR}$ is a serine/threonine protein kinase that regulates cell proliferation, migration, survival, and metabolism, and apoptosis of S6 kinase 1, a substrate of mTOR complex 1 that phosphorylates and subsequently activates the ER. ${ }^{43}$ Resistance may also occur because of cross talk between the ER and growth factor receptor signaling pathways, including members of the epidermal growth factor receptor (EGFR) family, such as EGFR, human epidermal growth factor receptor 2 (HER2) and insulin-like growth factor 1 receptor (IGFR1), which activate downstream signaling pathways, including the PI3K/Akt/mTOR and mitogen-activated protein kinase pathways. $^{23,34,38}$

\section{Approaches to managing resistance to endocrine therapy}

Selective ER downregulators, which have a mechanism of action distinct from that of AIs and tamoxifen, are being utilized in the setting of endocrine-resistant breast cancer, ${ }^{44-46}$ with data available for patients with visceral disease. ${ }^{24,46}$ In recognition of the cross talk between the ER and other signaling pathways, new targeted therapies are also being explored in combination with endocrine therapies, representing a new strategy to overcome endocrine resistance. ${ }^{47}$ Among the various approaches being investigated, inhibition of the mTOR pathway is one of the most promising. ${ }^{48}$ Other targeted therapies being evaluated in combination with endocrine therapies include HER2, EGFR, histone deacetylase, and cyclin-dependent kinase 4/6 (CDK4/6) inhibitors. ${ }^{47,49-54}$ Clinical studies to date have evaluated the effectiveness of the combination of targeted agents with endocrine therapy in overcoming acquired resistance in patients with $\mathrm{HR}+\mathrm{ABC}$, including patients with visceral disease (Table 1). ${ }^{49-58}$ Although few of these studies compared outcomes in patients with visceral vs nonvisceral disease, several studies reported the proportion of patients who had visceral disease; this might provide some indication of the effectiveness of these treatments in this population. Previous trials have also assessed combination chemotherapy and endocrine therapy in early $\mathrm{BC}$ and $\mathrm{ABC}$; however, studies have provided conflicting results and demonstrated increased toxicity with the combination therapy. ${ }^{59-61}$

\section{Other endocrine therapies}

The selective ER downregulator fulvestrant (Faslodex ${ }^{\circledR}$; AstraZeneca Pharmaceuticals LP) is believed to delay resistance to endocrine therapy in a low-estrogen environment because of degradation of the ER, reducing cross talk between the ER and estrogen-independent growth factor receptor signaling pathways. ${ }^{42}$ Clinical studies have shown the effectiveness of fulvestrant in patients resistant to either AI or tamoxifen treatment, including patients with visceral disease. ${ }^{44-46}$ The Evaluation of Faslodex versus Exemestane Clinical Trial (EFECT) showed that fulvestrant and exemestane had comparable efficacy and tolerability in patients with $\mathrm{ABC}$ after nonsteroidal AI failure, with a time to progression of 3.7 months with both treatments (hazard ratio: 0.96; $95 \%$ confidence interval [CI]: 0.82-1.13). ${ }^{44}$ In a retrospective analysis, clinical benefit was observed in $29 \%$ and $27 \%$ of patients with visceral metastases treated with either fulvestrant or exemestane, respectively. ${ }^{24}$

A retrospective analysis of two Phase III studies comparing fulvestrant and anastrozole reported a CBR of $38 \%$ and $37 \%$, respectively, in patients with visceral disease vs $48 \%$ and $44 \%$, respectively, in patients without visceral disease who previously underwent first-line endocrine therapy. ${ }^{45}$ In a Phase III trial of two fulvestrant doses $(250 \mathrm{mg}$ and $500 \mathrm{mg}$ ) in postmenopausal women with $\mathrm{HR}+\mathrm{ABC}$ who experienced progression after previous endocrine therapy, PFS was significantly longer with fulvestrant $500 \mathrm{mg}$ than with fulvestrant 


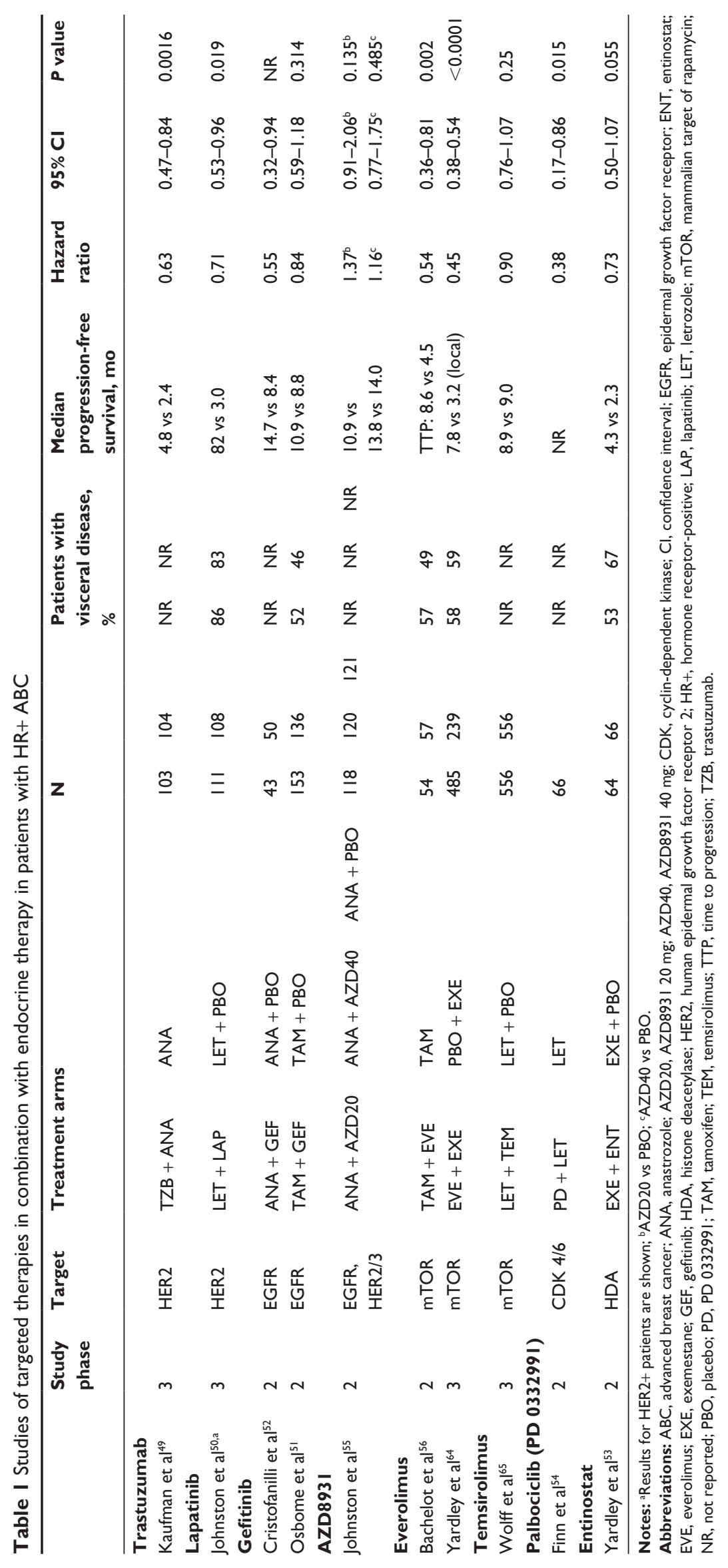


$250 \mathrm{mg}$ (hazard ratio: $0.80 ; 95 \%$ CI: $0.68-0.94) .{ }^{46}$ On the basis of these results, the approved dose of fulvestrant was increased from $250 \mathrm{mg}$ to $500 \mathrm{mg}$. In a subgroup analysis, PFS was significantly longer in patients with visceral disease treated with fulvestrant $500 \mathrm{mg}$ than in those treated with fulvestrant $250 \mathrm{mg}$ (hazard ratio: 0.86 ; 95\% CI: 0.70-1.06), as well as in patients without visceral disease (hazard ratio: 0.72; 95\% CI: 0.57-0.92).

\section{mTOR inhibitors}

In preclinical studies, the mTOR inhibitor everolimus (Afinitor ${ }^{\circledR}$; Novartis Pharmaceuticals Corporation) in combination with endocrine therapy, including AIs and selective ER modulators, showed synergistic inhibition of proliferation, apoptosis induction, and restoration of endocrine sensitivity. ${ }^{62,63}$ Two key clinical studies have shown that everolimus significantly improved time to progression in patients with $\mathrm{ER}+$ metastatic $\mathrm{BC}$ undergoing everolimus plus endocrine therapy for endocrine-resistant $\mathrm{HR}+\mathrm{ABC}$.

In the Phase II Tamoxifen Plus Everolimus (TAMRAD) study of 111 patients with HR+, HER2-negative (HER2-) metastatic $\mathrm{BC}$ and previous exposure to AIs, $53 \%$ of whom had visceral disease, the addition of everolimus to tamoxifen delayed time to disease progression and improved OS. ${ }^{56}$ Time to progression was 8.6 months with everolimus plus tamoxifen and was 4.5 months with tamoxifen alone, corresponding to a $46 \%$ reduction in the risk of progression with the addition of everolimus (hazard ratio: 0.54 ; 95\% CI: $0.36-0.81$ ). OS was not reached for the everolimus plus tamoxifen arm and was 32.9 months in the tamoxifen-alone arm, resulting in a $55 \%$ reduction in the risk of death (hazard ratio: $0.45 ; 95 \%$ CI: $0.24-0.81)$.

In the randomized, placebo-controlled, Phase III Breast Cancer Trials of Oral Everolimus-2 (BOLERO-2) study, the combination of everolimus and exemestane was evaluated in 724 postmenopausal women with $\mathrm{HR}+\mathrm{ABC}$ progressing or recurring after nonsteroidal AI therapy. ${ }^{57,58,64}$ At the final analysis after a median follow-up of 18 months, median PFS based on investigator assessment was 7.8 months in the everolimus plus exemestane arm and 3.2 months in the placebo plus exemestane arm (hazard ratio: $0.45 ; 95 \% \mathrm{CI}$ : $0.38-0.54 ; P<0.0001) .58,64$ Consistent results were also observed based on independent central assessment (11.0 months with everolimus and exemestane vs 4.1 months with placebo plus exemestane).

In a prespecified exploratory analysis of the BOLERO-2 study, the efficacy and safety of everolimus plus exemestane were evaluated according to the presence of visceral disease, with visceral disease reported in $56 \%$ of patients. ${ }^{8}$ Of these patients, $84 \%$ had two or more metastatic sites and $50 \%$ had three or more metastatic sites. Metastatic sites included the lung (in $45 \%$ of patients) and liver (50\%), as well as metastases to both sites (14\%). Among patients with visceral metastases, median PFS was 6.8 months in the everolimus plus exemestane arm and was 2.8 months in the placebo plus exemestane arm by local investigator assessment (hazard ratio: 0.47 ; 95\% CI: $0.37-0.60 ; P<0.05)$. Similarly, among patients without visceral metastases, median PFS was 9.9 months in the everolimus plus exemestane arm and 4.2 months in the placebo plus exemestane arm (hazard ratio: $0.41 ; 95 \% \mathrm{CI}$ : $0.31-0.55 ; P<0.05)$. Improvement in PFS with everolimus plus exemestane was seen in all patients irrespective of Eastern Cooperative Oncology Group (ECOG) performance status, with patients with visceral metastases and an ECOG performance status of 0 having a median PFS of 6.8 months in the everolimus plus exemestane arm and 2.8 months with placebo plus exemestane. In patients with visceral metastases and an ECOG performance status of at least 1, everolimus more than tripled the median PFS compared with that of placebo plus exemestane (6.8 vs 1.5 months). CBR was also significantly higher among patients treated with everolimus plus exemestane than with placebo plus exemestane, and this effect was irrespective of visceral involvement (no visceral disease at baseline: $59.8 \%$ vs $31.7 \%$; visceral disease at baseline: $44.6 \%$ vs $22.2 \%$,). Patients with visceral disease had a similar CBR with everolimus plus exemestane, independent of ECOG performance status.

In these studies, the safety profile of everolimus was consistent with that reported in previous studies. ${ }^{56-58}$ In the TAMRAD study, stomatitis, rash, diarrhea, fatigue, anorexia, and infection were more common among recipients of everolimus plus tamoxifen than those who received tamoxifen alone. ${ }^{56}$ Most adverse events (AEs) were grade $1 / 2$, and the incidence of nonhematologic grade $3 / 4$ AEs was comparable with that in the combination arm.

In the BOLERO-2 study, combination therapy was also associated with a higher incidence of AEs. ${ }^{57}$ The most common grade $3 / 4$ AEs in the everolimus plus exemestane arm were stomatitis ( $8 \%$ vs $1 \%$ with placebo plus exemestane), anemia ( $6 \%$ vs $<1 \%$ ), dyspnea ( $4 \%$ vs $1 \%$ ), hyperglycemia ( $4 \%$ vs $<1 \%$ ), fatigue ( $4 \%$ vs $1 \%$ ), and pneumonitis ( $3 \%$ vs $0 \%)$. The incidence of AEs was similar in patients with or without visceral disease, with no increased risk for a specific $\mathrm{AE}$ in patients with visceral metastases. ${ }^{8}$ The most common treatment-emergent AEs for patients receiving everolimus plus exemestane with visceral vs nonvisceral disease 
were stomatitis (59\% and 59\%, respectively), rash (40\% and $39 \%$, respectively), fatigue ( $40 \%$ and $36 \%$, respectively), decreased appetite (36\% and $24 \%$, respectively), and diarrhea (34\% and 34\%, respectively). The frequency and type of these AEs were consistent with those seen in the overall study population.

Results from these studies support the addition of an mTOR inhibitor to increase sensitivity to endocrine therapy with tamoxifen or exemestane. In particular, the subanalysis of BOLERO-2 highlights that everolimus, in combination with exemestane, might be an alternative to chemotherapy for patients whose visceral metastasis is not immediately life-threatening. ${ }^{8}$

The ongoing Phase II study BOLERO-6 is evaluating everolimus in combination with exemestane vs everolimus alone vs capecitabine alone, in advanced, recurrent, or metastatic $\mathrm{BC}$ patients, after progression or recurrence with previous letrozole or anastrozole therapy (ClinicalTrials.gov identifier: NCT01783444). Other mTOR inhibitors undergoing clinical evaluation in advanced breast cancer include temsirolimus and ridaforolimus, although data in the setting of endocrine resistance and in patients with visceral disease are not available. ${ }^{65,66}$

\section{HER2-directed therapies}

Approximately half of HER2-positive (HER2+) BCs are HR+, and HER2 overexpression is associated with poor prognosis regardless of HR status, thus providing a rationale for combining HER2-directed therapy with endocrine treatment. ${ }^{23}$

Two Phase III studies evaluated HER2-directed therapy in combination with endocrine therapy in patients with HER2+ and HR+ metastatic BC. ${ }^{49,50}$ In the Trastuzumab and Anastrozole Directed Against ER-Positive HER2-Positive Mammary Carcinoma (TAnDEM) study, 207 patients received trastuzumab (Herceptin ${ }^{\circledR}$; Genentech, Inc., South San Francisco, CA, USA) plus anastrozole or anastrozole alone as first- or second-line endocrine therapy for ABC. ${ }^{49}$ The patients received previous adjuvant tamoxifen therapy or hormonal therapy for metastatic disease. The addition of trastuzumab to anastrozole significantly increased PFS (hazard ratio: $0.63 ; 95 \%$ CI: $0.47-0.84 ; P=0.0016$ ), but absolute improvement was modest, with a PFS of 4.8 months, with trastuzumab plus anastrozole and 2.4 months with anastrozole alone, and no significant difference in OS between the treatment arms was found. The proportion of patients with visceral disease was not reported in this study.
In another Phase III study, 1,286 patients received letrozole plus lapatinib (Tykerb ${ }^{\circledR}$; GlaxoSmithKline, Research Triangle Park, NC, USA) or letrozole plus placebo as first-line treatment of $\mathrm{HR}+$ metastatic $\mathrm{BC}$, which included a subset of HER2+ patients. ${ }^{50}$ No previous therapy for advanced or metastatic disease was allowed; however, previous neoadjuvant or adjuvant antiestrogen, AI, or trastuzumab therapy was allowed if completed more than 1 year before study entry. There was no significant improvement in PFS in patients with HR+ HER2 - tumors with the addition of lapatinib to letrozole (hazard ratio: $0.90 ; 95 \% \mathrm{CI}$ : $0.77-1.05$; $P=0.188$ ). In contrast, in patients with HR+/HER $2+$ tumors, the addition of lapatinib to letrozole significantly reduced the risk for disease progression vs letrozole plus placebo (hazard ratio: $0.71 ; 95 \%$ CI: $0.53-0.96 ; P=0.019$ ), with a median PFS of 8.2 vs 3.0 months. Notably, $85 \%$ of patients with HER2+ disease had visceral disease or soft-tissue involvement.

No new or unexpected AEs were reported in either study, although the incidence of some grade 3/4 AEs was more common with combination therapy. ${ }^{49,50}$ In the TAnDEM study, the incidence of grade 3 and 4 AEs was $23 \%$ and $5 \%$, respectively, in the trastuzumab plus anastrozole arm, and $15 \%$ and $1 \%$, respectively, in the anastrozole alone arm. ${ }^{49} \mathrm{In}$ the Phase III study of letrozole plus lapatinib or letrozole plus placebo, the most common AEs were diarrhea, rash, nausea, arthralgia, and fatigue, most of which were grade $1 / 2$; grade $3 / 4$ events were more common in the combination arm..$^{50}$ Results from both studies suggest that the combination of lapatinib or trastuzumab with anastrozole may provide some clinical benefit in patients with HR+/HER2+ ABC.

\section{EGFR-targeted therapies}

Preclinical studies demonstrating that members of the EGF and IGF families can modulate tamoxifen sensitivity and that increased expression of EGFR, HER2, and IGFR1 can elicit tamoxifen resistance have led to clinical studies evaluating EGFR-targeted therapies in combination with endocrine therapy for metastatic BC. ${ }^{23,32}$ Two Phase II studies evaluated the oral tyrosine kinase inhibitor gefitinib (Iressa $^{\circledR}$; AstraZeneca Pharmaceuticals LP) in combination with anastrozole or tamoxifen vs anastrozole or tamoxifen alone, in patients with HR+ metastatic BC. ${ }^{11,52}$ One study of 93 patients who had not received previous therapy for metastatic disease or in whom metastatic disease developed during or after adjuvant therapy reported that the addition of gefitinib to anastrozole significantly increased PFS (14.7 vs 8.4 months; hazard ratio: 0.55 ; $95 \%$ CI: $0.32-0.94) .{ }^{52}$ 
The proportion of patients with visceral disease was not reported in this study. No unexpected AEs were reported, although more treatment-related AEs leading to treatment discontinuation occurred in the combination arm than in the anastrozole plus placebo arm (21\% vs $4 \%)$. In contrast, the other Phase II study, which included 290 patients with recurrence during or after adjuvant AI therapy or in whom first-line AI therapy was unsuccessful, reported no significant improvement in PFS with the addition of gefitinib to tamoxifen (hazard ratio: 0.84 ; 95\% CI: $0.59-1.18$ ). ${ }^{51}$ In this study, $51 \%$ of patients had visceral disease.

Based on these conflicting results, it has been suggested that prescribing gefitinib or any other EGFR-tyrosine kinase inhibitor in combination with endocrine therapy in patients with $\mathrm{HR}+$ metastatic $\mathrm{BC}$ is not advisable. ${ }^{23} \mathrm{~A}$ Phase II, randomized placebo-controlled study of AZD8931, an inhibitor of EGFR, HER2, and HER3 signaling, was initiated in combination with anastrozole in HR+, HER2-, endocrine therapynaïve $A B C .{ }^{55}$ An interim analysis of this study reported no significant difference in PFS for AZD8931 $20 \mathrm{mg}$ (hazard ratio: 1.37 ; 95\% CI: 0.91-2.06; $P=0.135$ ) or AZD8931 $40 \mathrm{mg}$ (hazard ratio: $1.16 ; 95 \% \mathrm{CI}: 0.77-1.75 ; P=0.485$ ) compared with placebo. The proportion of patients with visceral disease was not reported in this study. Based on the results of this analysis, the study was closed on the recommendation of the independent data monitoring committee.

\section{Cyclin-dependent kinase inhibitors}

Preclinical studies have shown synergistic activity with the CDK4/6 inhibitor palbociclib (PD 0332991). ${ }^{54}$ An ongoing two-part Phase II study is evaluating first-line therapy with palbociclib in combination with letrozole or letrozole alone, in 66 patients with HR+ HER2-ABC. At data cutoff, PFS was significantly improved with the addition of palbociclib to letrozole (hazard ratio: 0.38 : 95\% CI: $0.17-0.86 ; P=0.015$ ). The most commonly reported treatment-related AEs in the combination arm were neutropenia, leukopenia, and fatigue. The proportion of patients with visceral disease was not reported in this study.

\section{Histone deacetylase inhibitors}

Preclinical studies have shown that the oral histone deacetylase inhibitor entinostat inhibits ER $\alpha$-positive tumor growth and restores tumor sensitivity through downregulation of estrogen-independent growth factor signaling, thereby increasing aromatase levels and normalizing ER $\alpha$ levels. ${ }^{53}$
A Phase II, randomized, placebo-controlled study of exemestane with or without entinostat in 130 postmenopausal women with locally recurrent or metastatic ER+ BC that had progressed during treatment with a nonsteroidal AI reported that exemestane plus entinostat improved PFS compared with exemestane plus placebo ( $4.3 \mathrm{vs} 2.3$ months) (hazard ratio: $0.73 ; 95 \% \mathrm{CI}: 0.50-1.07 ; P=0.055$ ). Median OS improved from 28.1 months with exemestane plus entinostat, compared with 19.8 months with exemestane plus placebo (hazard ratio: 0.59 ; 95\% CI: $0.36-0.97 ; P=0.036$ ).$^{53}$ The most frequently reported AEs in the entinostat plus exemestane group were fatigue, nausea, neutropenia, peripheral edema, vomiting, anemia, dyspnea, thrombocytopenia, decreased weight, diarrhea, and pain. A substantial proportion of patients $(60 \%)$ in this study had lung or liver visceral disease.

\section{QoL considerations in visceral disease}

The QoL of patients with $\mathrm{BC}$ is impacted by the effectiveness and AE profile of the therapeutic intervention, and it is wellestablished that treatment-related toxicities can adversely affect the QoL of patients with ABC.${ }^{67}$ For instance, chemotherapy can cause serious AEs, such as nausea, vomiting, myelosuppression, and infectious complications, as well as symptom clusters, such as insomnia, mood disturbances, pain, and fatigue, ${ }^{8,22,24,67}$ and AIs can cause hot flashes, arthralgia, vaginal dryness, and dyspareunia, ${ }^{6,22,68,69}$ all of which can negatively affect QoL. Because treatment-related toxicity and painful visceral metastases can have a major impact on QoL, any new treatments or treatment regimens should, in addition to any clinical benefits, provide palliation and maximize QoL. ${ }^{67}$

Few of the clinical studies of endocrine therapy and targeted agent combinations in patients with endocrine resistance highlighted in this review evaluated QoL. However, QoL was assessed as a secondary objective in the BOLERO-2 trial of everolimus plus exemestane vs exemestane alone. ${ }^{67}$ Results from this study showed that everolimus in combination with exemestane was associated with a longer time to definitive deterioration in global health-related QoL (HRQoL) than was placebo plus exemestane alone. The median time to definitive deterioration in HRQoL was 8.3 months with everolimus plus exemestane and 5.8 months with placebo plus exemestane (hazard ratio: $0.74 ; P=0.0084$ ). A subgroup analysis of various patient- and disease-related variables on the time to definitive deterioration of global 
HRQoL found no significant differences between patients with or without visceral metastases.

Additional post hoc analyses of HRQoL outcomes from the BOLERO-2 trial at a median follow-up of 18 months were recently reported. ${ }^{70}$ Consistent with the initial analysis, no statistically significant overall difference in HRQoL outcomes between treatment arms was found, indicating that everolimus combined with exemestane provides clinical benefit without adversely affecting QoL. In a sensitivity analysis assessing the effect of study discontinuation on or before week 24 of treatment, patients who dropped out early from the study had a more severe HRQoL decline with both treatments, whereas patients treated with everolimus plus exemestane who did not drop out early had stable HRQoL outcomes relative to those receiving placebo plus exemestane.

The QoL results from BOLERO-2 provide additional support for the benefit of everolimus plus exemestane in patients with $\mathrm{ABC}$ in whom disease progressed after treatment with nonsteroidal AIs. Further studies are needed that evaluate HRQoL for new treatment regimens currently being investigated in endocrine-resistant $\mathrm{HR}+\mathrm{ABC}$.

\section{Conclusion}

Although endocrine therapies have been the mainstay of treatment for postmenopausal women with $\mathrm{HR}+\mathrm{ABC}$, their long-term efficacy is limited because of the development of resistance. In addition, many patients with $\mathrm{HR}+\mathrm{ABC}$ present with visceral disease, which is associated with a poor prognosis. Contrary to current perceptions, patients with visceral disease can be treated with endocrine therapy rather than chemotherapy. Because there is considerable cross talk between the ER and other signaling pathways, several targeted therapies are being investigated in combination with endocrine therapy for the treatment of patients with HR+ ABC whose tumors are endocrine-resistant. Studies investigating endocrine therapy with targeted agents have mostly focused on patients with $\mathrm{HR}+\mathrm{ABC}$. However, data from a prespecified analysis of the BOLERO-2 study have shown promising clinical benefit with everolimus plus exemestane in $\mathrm{HR}+\mathrm{ABC}$ patients with visceral disease that progresses after therapy with nonsteroidal AIs.

\section{Acknowledgments}

Editorial support in the preparation of this manuscript was provided by Tricia Newell, PhD, Mark English, PhD, and Matthew Grzywacz, PhD (ApotheCom, Yardley, PA, USA). This editorial support was funded by Novartis Pharmaceuticals Corporation.

\section{Disclosure}

The author reports no conflicts of interest in this work.

\section{References}

1. Jemal A, Bray F, Center MM, Ferlay J, Ward E, Forman D. Global cancer statistics. CA Cancer J Clin. 2011;61(2):69-90.

2. American Cancer Society. Cancer Facts and Figures 2014. Atlanta, GA: American Cancer Society; 2014.

3. Setiawan VW, Monroe KR, Wilkens LR, Kolonel LN, Pike MC, Henderson BE. Breast cancer risk factors defined by estrogen and progesterone receptor status: the multiethnic cohort study. Am J Epidemiol. 2009;169(10):1251-1259.

4. Cooper JA, Rohan TE, Cant EL, Horsfall DJ, Tilley WD. Risk factors for breast cancer by oestrogen receptor status: a population-based casecontrol study. Br J Cancer. 1989;59(1):119-125.

5. Pritchard KI. Endocrine therapy: is the first generation of targeted drugs the last? J Intern Med. 2013;274(2):144-152.

6. Buijs C, de Vries EG, Mourits MJ, Willemse PH. The influence of endocrine treatments for breast cancer on health-related quality of life. Cancer Treat Rev. 2008;34(7):640-655.

7. National Comprehensive Cancer Network. NCCN Clinical Practice Guidelines in Oncology ${ }^{\circledR}$. Breast Cancer. Version 1.2014. Fort Washington, PA: National Comprehensive Cancer Network; 2014.

8. Campone M, Bachelot T, Gnant M, et al. Effect of visceral metastases on the efficacy and safety of everolimus in postmenopausal women with advanced breast cancer: subgroup analysis from the BOLERO-2 study. Eur J Cancer. 2013;49(12):2621-2632.

9. Cardoso F, Bischoff J, Brain E, et al. A review of the treatment of endocrine responsive metastatic breast cancer in postmenopausal women. Cancer Treat Rev. 2013;39(5):457-465.

10. Cruz Jurado J, Richart Aznar P, Garcia Mata J, et al. Management of patients with metastatic breast cancer. Adv Ther. 2011;28(Suppl 6):S50-S65.

11. Bergh J, Jönsson PE, Lidbrink EK, et al. FACT: an open-label randomized phase III study of fulvestrant and anastrozole in combination compared with anastrozole alone as first-line therapy for patients with receptor-positive postmenopausal breast cancer. J Clin Oncol. 2012;30(16):1919-1925.

12. Gibson L, Lawrence D, Dawson C, Bliss J. Aromatase inhibitors for treatment of advanced breast cancer in postmenopausal women. Cochrane Database Syst Rev. 2009;4:CD003370.

13. Higgins MJ, Baselga J. Targeted therapies for breast cancer. $J$ Clin Invest. 2011;121(10):3797-3803.

14. American Cancer Society. Breast Cancer Facts and Figures: 2013-2014. Atlanta, GA: American Cancer Society; 2013.

15. Johnson RH, Chien FL, Bleyer A. Incidence of breast cancer with distant involvement among women in the United States, 1976 to 2009. JAMA. 2013;309(8):800-805.

16. Rosa Mendoza ES, Moreno E, Caguioa PB. Predictors of early distant metastasis in women with breast cancer. J Cancer Res Clin Oncol. 2013;139(4):645-652.

17. Solomayer EF, Diel IJ, Meyberg GC, Gollan C, Bastert G. Metastatic breast cancer: clinical course, prognosis and therapy related to the first site of metastasis. Breast Cancer Res Treat. 2000;59(3):271-278.

18. Insa A, Lluch A, Prosper F, Marugan I, Martinez-Agullo A, Garcia-Conde J. Prognostic factors predicting survival from first recurrence in patients with metastatic breast cancer: analysis of 439 patients. Breast Cancer Res Treat. 1999;56(1):67-78.

19. Mouridsen H, Gershanovich M, Sun Y, et al. Superior efficacy of letrozole versus tamoxifen as first-line therapy for postmenopausal women with advanced breast cancer: results of a phase III study of the International Letrozole Breast Cancer Group. J Clin Oncol. 2001;19(10): 2596-2606.

20. Yardley DA. Visceral disease in patients with metastatic breast cancer: efficacy and safety of treatment with ixabepilone and other chemotherapeutic agents. Clin Breast Cancer. 2010;10(1):64-73. 
21. Howell A, Robertson JF, Vergote I. A review of the efficacy of anastrozole in postmenopausal women with advanced breast cancer with visceral metastases. Breast Cancer Res Treat. 2003;82(3):215-222.

22. Wilcken N, Hornbuckle J, Ghersi D. Chemotherapy alone versus endocrine therapy alone for metastatic breast cancer. Cochrane Database Syst Rev. 2003;2:CD002747.

23. Johnston SRD, Schiavon G. Treatment algorithms for hormone receptor-positive advanced breast cancer: going forward in endocrine therapy - overcoming resistance and introducing new agents. Am Soc Clin Oncol Educ Book. 2013;2013:e28.

24. Mauriac L, Romieu G, Bines J. Activity of fulvestrant versus exemestane in advanced breast cancer patients with or without visceral metastases: data from the EFECT trial. Breast Cancer Res Treat. 2009;117(1):69-75.

25. Barrios CH, Sampaio C, Vinholes J, Caponero R. What is the role of chemotherapy in estrogen receptor-positive, advanced breast cancer? Ann Oncol. 2009;20(7):1157-1162.

26. Smith NZ. Treating metastatic breast cancer with systemic chemotherapies: current trends and future perspectives. Clin J Oncol Nurs. 2012;16(2):E33-E43.

27. Pritchard KI, Gelmon KA, Rayson D, et al. Endocrine therapy for postmenopausal women with hormone receptor-positive her2-negative advanced breast cancer after progression or recurrence on nonsteroidal aromatase inhibitor therapy: a Canadian consensus statement. Curr Oncol. 2013;20(1):48-61.

28. Campos SM, Guastalla JP, Subar M, Abreu P, Winer EP, Cameron DA. A comparative study of exemestane versus anastrozole in patients with postmenopausal breast cancer with visceral metastases. Clin Breast Cancer. 2009;9(1):39-44.

29. García-Becerra R, Santos N, Díaz L, Camacho J. Mechanisms of resistance to endocrine therapy in breast cancer: Focus on signaling pathways, miRNAs and genetically based resistance. Int $J$ Mol Sci. 2012;14(1):108-145.

30. Moy B, Goss PE. Estrogen receptor pathway: resistance to endocrine therapy and new therapeutic approaches. Clin Cancer Res. 2006;12(16):4790-4793

31. Contreras-Yáñez I, Ponce De León S, Cabiedes J, Rull-Gabayet M, Pascual-Ramos V. Inadequate therapy behavior is associated to disease flares in patients with rheumatoid arthritis who have achieved remission with disease-modifying antirheumatic drugs. Am J Med Sci. 2010;340(4):282-290.

32. Musgrove EA, Sutherland RL. Biological determinants of endocrine resistance in breast cancer. Nat Rev Cancer. 2009;9(9):631-643.

33. Dodwell D, Wardley A, Johnston S. Postmenopausal advanced breast cancer: options for therapy after tamoxifen and aromatase inhibitors. Breast. 2006;15(5):584-594.

34. Provenzano A, Kurian S, Abraham J. Overcoming endocrine resistance in breast cancer: role of the PI3K and the mTOR pathways. Expert Rev Anticancer Ther. 2013;13(2):143-147.

35. Madaio RA, Spalletta G, Cravello L, Ceci M, Repetto L, Naso G. Overcoming endocrine resistance in breast cancer. Curr Cancer Drug Targets. 2010;10(5):519-528.

36. Morgensztern D, McLeod HL. PI3K/Akt/mTOR pathway as a target for cancer therapy. Anticancer Drugs. 2005;16(8):797-803.

37. Advani SH. Targeting mTOR pathway: A new concept in cancer therapy. Indian J Med Paediatr Oncol. 2010;31(4):132-136.

38. Osborne CK, Schiff R. Estrogen-receptor biology: continuing progress and therapeutic implications. J Clin Oncol. 2005;23(8):1616-1622.

39. Vilquin P, Villedieu M, Grisard E, et al. Molecular characterization of anastrozole resistance in breast cancer: pivotal role of the Akt/mTOR pathway in the emergence of de novo or acquired resistance and importance of combining the allosteric Akt inhibitor MK-2206 with an aromatase inhibitor. Int J Cancer. 2013;133(7): 1589-1602.

40. Manavathi B, Dey O, Gajulapalli VN, Bhatia RS, Bugide S, Kumar R. Derailed estrogen signaling and breast cancer: an authentic couple. Endocr Rev. 2013;34(1):1-32.
41. Chang J, Fan W. Endocrine therapy resistance: current status, possible mechanisms and overcoming strategies. Anticancer Agents Med Chem. 2013;13(3):464-475.

42. Tan PS, Haaland B, Montero AJ, Lopes G. A meta-analysis of anastrozole in combination with fulvestrant in the first line treatment of hormone receptor positive advanced breast cancer. Breast Cancer Res Treat. 2013;138(3):961-965.

43. Gnant M. The role of mammalian target of rapamycin (mTOR) inhibition in the treatment of advanced breast cancer. Curr Oncol Rep. 2013;15(1):14-23.

44. Chia S, Gradishar W, Mauriac L, et al. Double-blind, randomized placebo controlled trial of fulvestrant compared with exemestane after prior nonsteroidal aromatase inhibitor therapy in postmenopausal women with hormone receptor-positive, advanced breast cancer: results from EFECT. J Clin Oncol. 2008;26(10):1664-1670.

45. Mauriac L, Pippen JE, Quaresma Albano J, Gertler SZ, Osborne CK. Fulvestrant (Faslodex) versus anastrozole for the second-line treatment of advanced breast cancer in subgroups of postmenopausal women with visceral and non-visceral metastases: combined results from two multicentre trials. Eur J Cancer. 2003;39(9):1228-1233.

46. Di Leo A, Jerusalem G, Petruzelka L, et al. Results of the CONFIRM phase III trial comparing fulvestrant $250 \mathrm{mg}$ with fulvestrant $500 \mathrm{mg}$ in postmenopausal women with estrogen receptor-positive advanced breast cancer. J Clin Oncol. 2010;28(30):4594-4600.

47. Shtivelband MI. Everolimus in hormone receptor-positive advanced breast cancer: Targeting receptor-based mechanisms of resistance. Breast. 2013;22(4):405-410.

48. Yardley DA. Combining mTOR inhibitors with chemotherapy and other targeted therapies in advanced breast cancer: Rationale, clinical experience, and future directions. Breast Cancer (Auckl). 2013;7:7-22.

49. Kaufman B, Mackey JR, Clemens MR, et al. Trastuzumab plus anastrozole versus anastrozole alone for the treatment of postmenopausal women with human epidermal growth factor receptor 2-positive, hormone receptor-positive metastatic breast cancer: results from the randomized phase III TAnDEM study. J Clin Oncol. 2009;27(33):5529-5537.

50. Johnston S, Pippen J Jr, Pivot X, et al. Lapatinib combined with letrozole versus letrozole and placebo as first-line therapy for postmenopausal hormone receptor-positive metastatic breast cancer. J Clin Oncol. 2009;27(33):5538-5546.

51. Osborne CK, Neven P, Dirix LY, et al. Gefitinib or placebo in combination with tamoxifen in patients with hormone receptor-positive metastatic breast cancer: a randomized phase II study. Clin Cancer Res. 2011;17(5):1147-1159.

52. Cristofanilli M, Valero V, Mangalik A, et al. Phase II, randomized trial to compare anastrozole combined with gefitinib or placebo in postmenopausal women with hormone receptor-positive metastatic breast cancer. Clin Cancer Res. 2010;16(6):1904-1914.

53. Yardley DA, Ismail-Khan RR, Melichar B, et al. Randomized phase II, double-blind, placebo-controlled study of exemestane with or without entinostat in postmenopausal women with locally recurrent or metastatic estrogen receptor-positive breast cancer progressing on treatment with a nonsteroidal aromatase inhibitor. J Clin Oncol. 2013;31(17):2128-2135.

54. Finn RS, Crown JP, Boer K, et al. Results of a randomized Phase 2 study of PD 0332991, a cyclin-dependent kinase (CDK) 4/6 inhibitor, in combination with letrozole vs letrozole alone for first-line treatment of ER+/HER2- advanced breast cancer (BC) [abstract 100O]. Ann Oncol. 2012;23(suppl 2):ii43-ii45.

55. Johnston SRD, Basik M, Hegg R, et al. Phase II randomized study of the EGFR, HER2, HER3 signaling inhibitor AZD8931 in combination with anastrozole (A) in women with endocrine therapy (ET) naive advanced breast cancer (MINT) [abstract]. J Clin Oncol. 2013;Suppl 31:S531.

56. Bachelot T, Bourgier C, Cropet C, et al. Randomized phase II trial of everolimus in combination with tamoxifen in patients with hormone receptor-positive, human epidermal growth factor receptor 2-negative metastatic breast cancer with prior exposure to aromatase inhibitors: a GINECO study. J Clin Oncol. 2012;30(22):2718-2724. 
57. Baselga J, Campone M, Piccart M, et al. Everolimus in postmenopausal hormone receptor-positive advanced breast cancer. $N$ Engl J Med. 2012;366:520-529.

58. AFINITOR ${ }^{\circledR}$ (everolimus) $2.5 \mathrm{mg}$ tablets, $5 \mathrm{mg}$ tablets, $10 \mathrm{mg}$ tablets [package insert]. East Hanover, NJ: Novartis Pharmaceuticals Corporation; 2014.

59. Kardinal CG, Perry MC, Weinberg V, Wood W, Ginsberg S, Raju RN. Chemoendocrine therapy vs chemotherapy alone for advanced breast cancer in postmenopausal women: preliminary report of a randomized study. Breast Cancer Res Treat. 1983;3(4):365-371.

60. Boccardo F, Guglielmini P, Parodi A, Rubagotti A. Chemotherapy versus tamoxifen versus chemotherapy plus tamoxifen in node-positive, oestrogen receptor-positive breast cancer patients. Very late results of the 'gruppo di ricerca per la chemio-ormonoterapia adiuvante (GROCTA)' 01-Trial in early breast cancer. Breast Cancer Res Treat. 2011;126(3):653-661.

61. Colleoni M, Li S, Gelber RD, et al. Timing of CMF chemotherapy in combination with tamoxifen in postmenopausal women with breast cancer: role of endocrine responsiveness of the tumor. Ann Oncol. 2005;16(5):716-725.

62. Boulay A, Rudloff J, Ye J, et al. Dual inhibition of mTOR and estrogen receptor signaling in vitro induces cell death in models of breast cancer. Clin Cancer Res. 2005;11(14):5319-5328.

63. deGraffenried LA, Friedrichs WE, Russell DH, et al. Inhibition of mTOR activity restores tamoxifen response in breast cancer cells with aberrant Akt Activity. Clin Cancer Res. 2004;10(23):8059-8067.
64. Yardley DA, Noguchi S, Pritchard KI, et al. Everolimus plus exemestane in postmenopausal patients with $\mathrm{HR}(+)$ breast cancer: BOLERO-2 final progression-free survival analysis. Adv Ther. 2013;30(10):870-884.

65. Wolff AC, Lazar AA, Bondarenko I, et al. Randomized phase III placebo-controlled trial of letrozole plus oral temsirolimus as first-line endocrine therapy in postmenopausal women with locally advanced or metastatic breast cancer. J Clin Oncol. 2013;31(2):195-202.

66. Jerusalem G, Rorive A, Collignon J. Use of mTOR inhibitors in the treatment of breast cancer: an evaluation of factors that influence patient outcomes. Breast Cancer (Dove Med Press). 2014;6:43-57.

67. Burris HA, Lebrun F, Rugo HS, et al. Health-related quality of life of patients with advanced breast cancer treated with everolimus plus exemestane versus placebo plus exemestane in the phase 3, randomized, controlled, BOLERO-2 trial. Cancer. 2013;119(10):1908-1915.

68. van Nes JG, Fontein DB, Hille ET, et al. Quality of life in relation to tamoxifen or exemestane treatment in postmenopausal breast cancer patients: a Tamoxifen Exemestane Adjuvant Multinational (TEAM) Trial side study. Breast Cancer Res Treat. 2012;134(1):267-276.

69. Dixon JM, Renshaw L, Langridge C, et al. Anastrozole and letrozole: an investigation and comparison of quality of life and tolerability. Breast Cancer Res Treat. 2011;125(3):741-749.

70. Campone M, Beck JT, Gnant M, et al. Health-related quality of life and disease symptoms in postmenopausal women with $\mathrm{HR}(+)$, HER2(-) advanced breast cancer treated with everolimus plus exemestane versus exemestane monotherapy. Curr Med Res Opin. 2013;29(11):1463-1473.

\section{Publish your work in this journal}

Cancer Management and Research is an international, peer-reviewed open access journal focusing on cancer research and the optimal use of preventative and integrated treatment interventions to achieve improved outcomes, enhanced survival and quality of life for the cancer patient. The journal welcomes original research, clinical \& epidemiological

\section{Dovepress}

studies, reviews \& evaluations, guidelines, expert opinion \& commentary, case reports \& extended reports. The manuscript management system is completely online and includes a very quick and fair peerreview system, which is all easy to use. Visit http://www.dovepress.com/ testimonials.php to read real quotes from published authors 